\title{
Continued Usage and Location Disclosure of Location-Based Applications: A Necessity for Location Intelligence
}

\author{
Mehrdad Koohikamali \\ University of Redlands \\ Mehrdad_Koohikamali@redlands.edu
}

\author{
Mohammadreza Mousavizadeh \\ Western Michigan University \\ M.Mousavizadeh@wmich.edu
}

\author{
Dan Peak \\ University of North Texas \\ Daniel.Peak@unt.edu
}

\begin{abstract}
Location-based applications (LBA) have been widely accepted and used for different purposes ranging from navigation to dating or gaming. Most LBAs ask users to provide access to location data for more efficient and personalized location-based services. Location intelligence as an emerging area of business intelligence relies heavily on disclosing location information by users. This research builds a continuance usage and location disclosure model from the expectation-confirmation perspective. The effect of benefit expectations on usefulness and satisfaction is hypothesized. In addition, the positive effect of usefulness on satisfaction and continuance intention is postulated. After collecting survey data from main $L B A$ users, the results of the analysis support the proposed model. Findings contribute to the current literature in business intelligence by focusing on location disclosure behavior in the context of LBAs and the necessity of this type of information for location intelligence.
\end{abstract}

\section{Introduction}

The increasing usage of mobile applications is coupled with the continuous stream of locational information with the movement of smartphones. Overall, mobile app usage grew 6\% in 2017 and forecasts project 189 billion US dollars in revenues, with the most popular apps being utilities, social networking, tools, communication, travel, and local [62]. Unsurprisingly, rapid growth of this significant area is beset by unresolved concerns, such as problematic mobile app continuance and disclosure issues experienced by the growing diversity of smartphone users. This research focuses on these important areas because success of many businesses is dependent on the availability of location information generated constantly by users

Locational information has become integral to smartphone mobile apps, which have provided numerous valuable tools and services by accessing user information. For example, user location services have become an accepted and indispensable feature of mobile communication. These features have been on the rise since 2014, such that popular apps typically rely on location information to customize their functionalities [61].

Default smartphone settings facilitate location sharing, which is often standard user behavior. More than $90 \%$ of smartphone owners use location-based smartphone services [22]. About 74\% obtain destination directions based on their current device location. Over 50\% download mobile apps of various kinds and $85 \%$ of these share their location when they download and use apps [50]. A lesser $30 \%$ of social media users automatically allow mobile apps to display their location when they post [50].

Notwithstanding, users have become more cautious about when and what location information they choose to share [23]. While full functionality of many mobile apps rely on the user disclosing location information, people are usually hesitant to reveal their whereabouts without receiving sufficient value in return [23, 35].

Location-based apps (LBAs) work only when the requisite location information is available [54]. LBAs provide users with tailored, customized, personalized, and proximity-based functionalities using the physical geographical location of the mobile device [47]. LBAs allow app providers to access to a real-time user's location information throughout the life of the app. Research indicates that one-third of all mobile apps use location information provided by GPS-enabled smartphones, ostensibly to collect data that will help deliver better services [30]. For example, apps such as Instagram, Twitter, Yelp, Google Maps, Whisper, Snapchat, Walmart, and Starbucks require user location to provide customized and personalized services and features, otherwise they will underserve the user.

Potential advantages of LBAs are immense. Mobile systems that employ LBAs to track location 
open up abundant benefits for users and businesses [59]. Location intelligence, an IS area that uses LBAs, is an emerging trend in business intelligence and data analytics domains [51]. Location intelligence is the upcoming trend in business intelligence and data analytics domains [12]. In addition, LBAs are the next frontier in mobile technology because being able to track users' location opens up endless benefits for users and businesses [59]. According to a recent survey, $54 \%$ of business managers believe their business collect location data using mobile devices or apps [12]. Among challenges many organizations face, gathering real-time location data and ensuring the data quality are the two most important areas [12]. In location analytics, users of mobile apps and digital devices must overtly grant access to location information. However, not all users are comfortable with location sharing, as evidenced by a $6 \%$ decrease in checking-in for smartphone adult users [50].

Despite the potential benefits to mobile app users (73\% articulate that location sharing is somewhat or very useful), $63 \%$ nonetheless express discomfort with disclosing their location [57]. They remain reluctant, even as they are aware that withholding diminishes their overall experience [21]. On the other hand, users who are unaware of the benefits and experience a reduction in satisfaction may mistakenly choose to limit their usage of the app. Attempting to control personal privacy, $19 \%$ of cellphone users report they have turned off location tracking entirely [8].

LBAs that exhibit different features can shape varied user perceptions of app usefulness. For example, navigation apps essentially become useless to provide location-based services if the user location information is inaccessible. Conversely, social networking apps can still be useful without accessing the user location. Other effects are less well known, which leads to our LBA research problem. Prior research has focused on privacy concerns of mobile app usage [13, 35], but accorded scant attention to analyzing user benefit expectations of LBAs, especially with respect to perceptions of app usefulness and user satisfaction. Recently, researchers have recognized the importance of location information as a separate area of inquiry, known as location intelligence and analytics [51]. The absence of scholarly attention to continued usage LBAs leads us to call for more attention to this area [69].

The extracted value from data available to businesses could be maximized if the location data strategies and location intelligence can inform actionable decisions [26]. According to the result of a survey of 200 executives, $54 \%$ believe that location is collected through mobile apps in their organization [12]. If users discontinue disclosing their location through mobile apps or do not use the LBAs, the success of location intelligence would be impossible. Surprisingly, little prior research has considered the significant benefits associated with mobile location disclosure [56]. Accordingly, the purpose of this research is to fill the perceived continuance usage and location disclosure research gaps that exist in mobile app research, specifically from the expectationconfirmation theory (ECT) perspective [5, 67]. The aforementioned research gaps lead us to pose following research questions: (1) From the ECT perspective, how is continuance usage of LBA affected by usefulness, satisfaction, and benefit expectations? (2) For LBAs, how are user continuance usage and disclosure related? To answer the proposed research questions, the current study views perception of expected benefits and usefulness through the lens of expectation-confirmation theory [5].

Thus, the main objective of this research is twofold: (1) to propose an expanded continuance usage intention of LBAs; and (2) to empirically test the proposed research model using the survey data collected from LBA. The proposed LBA model is tested with the survey data. Finally, the practical and theoretical impacts of this research are discussed.

\section{Literature Review}

\subsection{Location-based applications and location intelligence}

Few users demonstrate concern over just how thoroughly smartphones mirror their lives, appreciating instead the many capabilities and conveniences they offer beyond basic phone conversation [7]. Still, due to the rapid development of smartphones, asking the consumer to fully understand the implications of proliferating smartphone features is a tall order. In less than a decade, mobile phones have evolved from communication-only devices to sophisticated multi-tasking tools that contain numerous mobile apps, so that they have been characterized as the Swiss army knife of technology [58]. Mobile apps are software applications designed specifically for smartphones, tablets, and other mobile devices [60]. Location-based applications (LBAs) allow app providers to access to a real-time user's location information throughout the life of the app.

Location intelligence as an emerging subfield of data science spectrum and refers to the wide range of spatial analysis techniques to understand hidden patterns of spatially-based phenomenon, events, decisions, and behaviors. Location intelligence ultimate goal is to turn location data into desired business outcomes [12]. 
Most of data in the world has a spatial dimension that proves the importance of having access to user's locational data. Mobile devices, due to the ubiquitous nature of them can create stream of users' whereabouts. To achieve the goal of location analytics or effective location intelligence, having access to users' location is crucial.

\subsection{Perceived benefit expectations}

Perceived benefit is also a two-dimensional construct known as value dimensions [46]. Utilitarian dimension refers to the functional and practical benefits and hedonic dimension reelects the aesthetic and enjoyment benefits [18]. Perceived usefulness is used to measure utilitarian benefit and perceived enjoyment is used to capture the hedonic benefit [63].

The direct and indirect advantages of adopting an IS comprise the two main types of perceived benefits [38]. For example, online mobile banking accords users a wider selection of financial benefits over physical banking, as well as information transparency [38]. With risks, come potential benefits - otherwise a rational user would not take risks. Both have been shown to precede attitudes about privacy sharing [31, 48]. Sharing information about visited locations can positively impact society. If information about inferior locations is shared, all society will benefit from the experiences of a few users.

The perceived benefit is the reward that expected by the user [15]. Similar to this idea, research indicates that background context and perceived value will impact disclosure behavior [68]. Mobile app users decide to take risks in exchange for potential benefits of LBAs [2]. Xu et al. [73] found that general benefits positively influence intention to disclose location. LBAs provide benefits to users alongside the cost of imposing several risks to their privacy [53, 73]. During the continuing usage, users' behavior is re-formed due to actual experiences [34]. Consequently, in the context of LBAs, continued usage behavior is closely related with satisfaction of the app.

\subsection{LBAs continued use}

LBAs can collect and disclose user location information, either intentionally or unintentionally disclosed by users [66]. Intentional disclosure can occur when users check in to location-based apps (e.g., on the Foursquare app) or when they grant permission to navigation apps to calculate a destination route by using their current location (e.g. on the Google Map app). Unintentional disclosure can occur when users are unaware that a mobile app is collecting their location information (e.g., installing an app without realizing it collects location information). Chia et al.
[16] study show access permission decisions made by careful users are usually based on simple signals such as app ratings, popularity, and number of downloads.

In the many previous Information Systems (IS) studies, user satisfaction is the important gauge to the IS continuance behavior [5, 20]. Previous studies discuss user satisfaction has a strong effect on IS usage behavior and positive perceived net benefits reinforce subsequent usage of an IS [20]. A user's satisfaction is the feeling about the prior IS usages [5]. A postacceptance model of IS continuance built on the expectation confirmation theory (ECT) suggests satisfaction and usefulness are positively related with the IS continuance intention [5].

\section{Theoretical Background}

\subsection{Expectation confirmation theory}

The concept of cognitive dissonance has been applied to different theories in different contexts. Cognitive dissonance refers to the situation in which an individual perceive consistency among different things. The Cognitive Dissonance Theory (CDT) susgeests that in these situations the individual try tio minimize the existing inconsistency [24]. One of the theories which is built up based on CDT is expectation confirmation theory (ECT) [41]. Expectation confirmation model is one of the theories that applied in several IS research [5, 41, 67] to explain how users' satisfaction influences on their intention to use of information systems. ECT applied in different contexts to study variety of dependent variables such as users' reaction to services, employee's new software acceptance, and users' technology acceptance [9]. This theory was developed by Oliver [45] and applied by Bhattacherjee [5] in the electronic commerce context. Although this theory has been applied in different contexts, core concepts in every research in this domain are expectation and disconfirmation [45]. Oliver [45] argues that consumers' purchase decision creates a reference for consumers' comparative judgement. If a product outperforms than expected there is a positive disconfirmation and if the product performs poorer than expected, there is a negative disconfirmation. Positive disconfirmation increase consumers' satisfaction and their intention to purchase a product. Goal attainment theory developed by King [38] postulates that individuals' level of satisfaction is determined based on their initial goals and the extent to which the goals are attained [39]. In other words, this theory suggests that the level of satisfaction from performing a behavior is the result of cost-benefit calculus [76]. The original theory argues that individuals set several goals for most of their 
activities. Their level of satisfaction is determined by the extent to which the goals are attained.

Bhattacherjee [5] applied ECT and Technology Acceptance Model (TAM) to explain IS use continuance intention. Bhattacherjee [5] suggests that IS use continuance decision is similar to the consumers' repurchase decision in different ways. First, both decisions are followed by an initial experience with the system/product, second, this initial experience/use affects the decision, and third, may reverse the initial decision to use/buy a product. Acquiring the initial experience often has monetary or/and non- monetary costs for IS users. As it was discussed earlier the two major parts of ECT are expectation and confirmation. To be able to understand Bhattacherjee's post acceptance model of IS continuance, it is necessary to understand IS users' expectation in the IS research. Based upon TAM, perceived usefulness is an antecedent of users intention to continue to use IS [19, 29]. perceived usefulness was used as a measure of user expectation [5]. Therefore, Bhattacherjee argues that expectation of IS users in the post acceptance stage is not different from their perceived usefulness of the IS that they use. Internet users' level of satisfaction positively influences their intention to use of location services. Bhattacherjee argued that consumers' post-purchase behavior (repurchase intention) is the result of consumers' satisfaction. This study applies the Bhattacherjee's post acceptance model of IS continuance which was driven from ECT and TAM.

\subsection{Hypotheses development}

Using IS has some monetary and/or non-monetary cost for the users. Therefore, users expect to perceive some benefits from using the IS [5]. This is true in any context. For example in the context of organization, employees need to sacrifice time and the organization needs to spend money on acquiring an IS and training employees to use it. In the context of online shopping, online customers need to spend time on the internet, pay for utilities, and etc. to be able to shop online. All these users expect some benefits from using these systems. According to $\mathrm{Xu}$ et al. [73] LBS users perceive three different benefits fro disclosing their information. These three types of benefits are personalization, positioning, and timeliness. Personalization refers to the value that LBA users perceive from experiencing the personalized functions on LBA. Positioning and timeliness refer to the value that LBA user perceive from having access to information and services in the right time and at the right place [73]. Users benefit expectation refers to their anticipated gained through using an information system [39, 65]. When users expect more benefits from using LBAs, they are more likely to perceive the LBA useful. The reason is that they perceive benefits from using the system which fulfills the cost of using LBA. If the users expect no benefit from using the LBA then the LBA only cost them. Therefore, they are not going to perceive it helpful. Hence we propose:

H1: LBA Users' benefit expectation positively influences their perceived usefulness of LBA.

According to ECT, users' satisfaction is influenced by two factors: their expectation and the extent to which their expectation would be confirmed after usage $[5,9,45]$. A LBA user who expect to get more benefit from using the LBA are more likely to be satisfied after using LBA. The reason is that their initial expectation was set based on the rational decision of choosing a specific LBA among the others. According to Bhattacherjee [5], these rational users will not continue to use a system that cost them and does not have benefit for them. Thus, user' benefit expectation is associated with the satisfaction of LBA users. Those users whose expectation confirmed perceive LBA more useful.

According to Tam et al. [65], the confirmation of users' expectation influence perceived usefulness and consequently their satisfaction. Perceived usefulness and ease of use are constructs that were used by Davis [19] and many other researchers In IS as beliefs that influence IS post acceptance behaviors [5]. One of the major concequenses of post acceptance behavior is users'satisfaction. Therefore, we expect that LBA users who perceive the LBA as a useful application be more satisfied than those who do not have such perception. This leads to the following hypothesis:

H2: LBA Users' benefit expectation positively influences their satisfaction.

H3: LBA Users' perceived usefulness influences their satisfaction.

The level of satisfaction of LBA users positively affect their intention to use of LBA. According to Bhattacherjee [5] satisfied users are more likely to continue their behavior. Therefore, LBA users who are satisfied by attaining their goals are more intended to use LBA in the future compare to dissatisfied users. People have different goals or "expectations" at the beginning [45]. The extent to which these goals will be satisfied by the LBA services affect their intention to continue to use LBA. More satisfied users who achieved more of their goals than the others are more likely to use LBA in the future.

In addition to the satisfaction perceived usefulness is also associated with LBA user's intention to continue to use. The reason is that when an information system is useful, users get monetary and/or non-monetary benefits from using it [5]. Therefore, they are motivated to use it again to get more benefits. In fact, LBA users perceive several 
benefits from using these services. These benefits increase their satisfaction from LBA. One possible explanation for the positive effect of perceived benefits on satisfaction is that benefits of using LBA help users to achieve their goals and according to goal attainment theory [32] individuals will be more satisfied whenever they achieve their goals. Therefore, this study hypothesizes that:

H4: LBA users' satisfaction positively influences their intention to continue to use LBA.

H5: LBA Users' perceived usefulness positively influences their intention to continue to use LBA.

Theory of reasoned action suggests that individuals who are intended to perform a behavior are more likely to perform that behavior $[1,25]$. LBA users who are intended to continue to use LBA are more likely to share their location on LBA. One possible reason for is that they are satisfied with LBA and they want to benefit from using the LBA. To get benefit from an application whose core value creation process is based on users' location, location disclosure is inevitable. As a result, we suggest the following hypotheses:

H6: LBA Users' intention to continue to use LBA positively influences their location disclosure on LBA.

Based on the foregoing theories we developed the following research model (Figure 1) to study the antecedents of intention to continue to use LBAs.

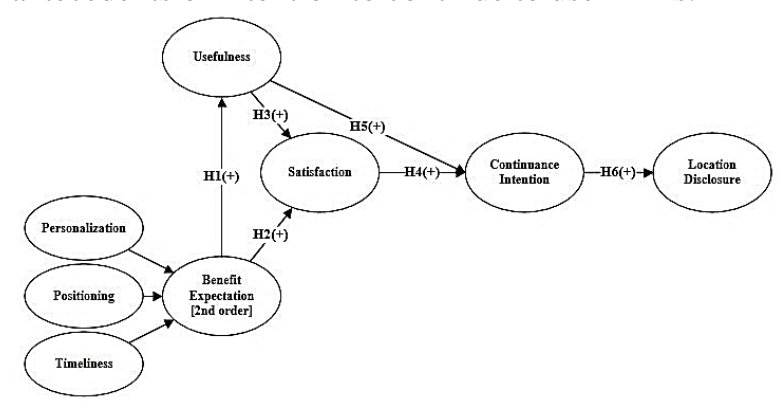

Figure 1. Proposed LBA continuance model

\section{Methodology}

\subsection{Study design and procedure}

To explain the antecedents of LBA usage behavior, this research develops a research model based on goal attainment theory integrated with expectationconfirmation theory. To collect the data used for testing the proposed model, a survey method is used. The measures of this research were all identified and adopted in the related literature, to achieve strong content validity [43]. Construct measurement items are developed on 7-point Likert scale ranging from strongly disagree to strongly agree. Personalization, positioning, and timeliness dimensions of perceived benefit were adopted from [73]. Perceived net goal attainment and satisfaction items were adopted from
[63]. Measurement items of intention to continue to use LBAs were adopted from [5]. The items and their sources are listed in Appendix A.

\subsection{Survey administration}

Online survey questionnaires were distributed to students enrolled in a large university in the US. Students are typical users of LBAs thus are excellent subjects to predict risk-benefit behavior. The collected sample dataset contained 350 samples, however there were several incomplete and missing response that were removed. In addition, we removed responses that are filled in less than 8 minutes as the average time needed to sufficiently read and answer the questionnaire. The final dataset contains total of 319 respondents. Table 1 lists demographic information of respondents. Respondents were asked to identify the main reasons to use LBAs. The main motives indicated by respondents to use LBAs are shown in Table 2 .

Table 1. Demographic information

\begin{tabular}{|c|c|}
\hline \multicolumn{2}{|c|}{ Gender } \\
\hline \multicolumn{2}{|c|}{ Male (53\%), Female (46\%), Other (1\%) } \\
\hline \multicolumn{2}{|c|}{ Age } \\
\hline \multicolumn{2}{|c|}{ Mean (22), Min (18), Max (49) } \\
\hline \multicolumn{2}{|c|}{ Academic standing } \\
\hline \multicolumn{2}{|c|}{$\begin{array}{l}\text { Freshman (1\%), Sophomore (24\%), Junior (52\%) } \\
\text { Senior }(21 \%) \text {, Graduate }(3 \%)\end{array}$} \\
\hline \multicolumn{2}{|c|}{ Dispensable income per year } \\
\hline Below $\$ 5,000$ & $57 \%$ \\
\hline$\$ 5,000-\$ 9,999$ & $22 \%$ \\
\hline$\$ 10,000-\$ 14,999$ & $10 \%$ \\
\hline$\$ 15,000-\$ 19,999$ & $3 \%$ \\
\hline Over $\$ 20,000$ & $8 \%$ \\
\hline
\end{tabular}

Table 2. Main Motivations to use LBAs

\begin{tabular}{|l|l|}
\hline \multicolumn{1}{|c|}{ Why do you use LBAs? } & Total Count (\%) \\
\hline Navigation & $180(56 \%)$ \\
\hline Find nearby places & $149(46 \%)$ \\
\hline Monitor traffic & $110(34 \%)$ \\
\hline Monitor weather & $106(33 \%)$ \\
\hline Connect to people around me & $96(30 \%)$ \\
\hline Find nearby events & $68(21 \%)$ \\
\hline Get news around me & $49(15 \%)$ \\
\hline View people's activities around me & $47(15 \%)$ \\
\hline Geo-tag on social networks & $47(15 \%)$ \\
\hline Track my fitness activity & $28(9 \%)$ \\
\hline Find nearby parking & $28(9 \%)$ \\
\hline Find a ride & $20(6 \%)$ \\
\hline Find nearby sights & $12(4 \%)$ \\
\hline Play location-based games & $7(2 \%)$ \\
\hline
\end{tabular}


Table 3. Usage frequency

\begin{tabular}{|l|c|}
\hline \multicolumn{2}{|c|}{ LBAs use frequency (per day in the last month) } \\
\hline None & $16(5 \%)$ \\
$1-3$ & $144(45 \%)$ \\
$4-6$ & $64(20 \%)$ \\
$7-9$ & $22(7 \%)$ \\
More than 10 & $73(23 \%)$ \\
\hline
\end{tabular}

\section{Data analysis}

The authors test the posited model with partial least squares (PLS) analysis, because PLS employs a component-based approach for estimation that minimizes residual distributions [17], and is best suited for testing complex relationships by avoiding inadmissible solutions and factor indeterminacy [14]. Furthermore, PLS is appropriate for modeling secondorder constructs [70]. Smart PLS 3 is the software used to test the measurement model because it allows to model latent constructs as formative/reflective [55]. To establish the reliability and validity of measures before analyzing the structural model, a two-step approach recommended by [3] is employed for data analysis. First, the analysis of the measurement is conducted to assess internal consistency, measurement reliability, convergent validity, and discriminant validity. Second, the structural relationship of latent constructs is analyzed. Perceived benefit construct is operationalized as second-order formative because dimensions form the latent variable and underlying dimensions are not highly correlated and are not interchangeable [49].

\subsection{Measurement model}

Two different approaches were used to assess measurement models of first-order reflective and second-order formative construct. To evaluate measurement model reliability and validity of firstorder constructs in PLS, item reliability, convergent validity and discriminant validity are presented. Appendix B represent descriptive statistics and correlation coefficients of research construct. To assess individual item reliability, inter-item loadings are examined. Factor loading above 0.7 represent sufficient reliability of items [28]. Results show, all inter-item loadings are higher than 0.7 and show adequate item reliability.

To evaluate convergent validity, the reliability of reflective first-order constructs, composite reliability, and average variance extracted (AVE) are assessed [27]. Cronbach's alpha and item loadings greater are used to assess construct reliability and composite reliability, correspondingly. Both measures are acceptable for values greater than 0.7 [44, 72]. AVE scores of 0.5 and more are desirable. Convergent validity is established by examining Cronbach's alpha values and AVEs in Appendix B.

To establish discriminant validity, inter-item correlations should be greater than outer loadings of constructs, square root of AVEs should be greater than its construct correlation, and correlation between constructs should be less than 0.85 threshold $[17,33]$. Factor loadings and Appendix B demonstrate both conditions for discriminant validity present, establishes discriminant validity of the measurement model. For second-order formative constructs, weights, variance inflation factors (VIFs), and the loadings were assessed and Warp PLS 5.0 is used to calculate corresponding values. All weights are significant and VIFs were less than 5, confirming the use of the second-order formative construct.

In a study with a survey questionnaire for data collection, researchers should check for the presence of common method bias to avoid erroneous conclusions [11]. In this research, common method bias is evaluated using Harman's single factor test and the Liang and Xue's [40] method. Harman's single factor test indicate common method bias may exist under two conditions. First, a single factor emerges from the un-rotated factor solution. Second, a single factor accounts for the majority of the variance within variables [52]. First, all the 26 items entered the explanatory factor analysis (EFA) and the un-rotated solution results in seven total factors, which equals the number of latent variables in the posited model. Second, the un-rotated single factors from the explanatory factor analysis accounts for $37.7 \%$ of the variance in the data which is less the $50 \%$ bound. Furthermore, threat of common method bias is examined following the procedure suggested by Liang and Xue [40]. According to the results, all the method factor loadings, except one are insignificant. Hence, neither of two indicators for common method bias occurred in this study.

\subsection{Structural model}

The structural model was estimated with Smart PLS 3. The explanatory power of the structural model is assessed through path coefficients and $\mathrm{R}$-square scores of endogenous variables. The obtained path coefficients and their corresponding significance level is shown in Figure 2. PLS does not directly support second-order factors. Hence, second-order constructs were operationalized using the repeated-indicators approach [42].

The PLS results indicate, all hypothesized paths were significant, expect the relationship between usefulness and continued intention to use. The results demonstrate the positive relationship between benefit expectations and usefulness $(\square=0.61, \mathrm{p}<0.001, \mathrm{H} 1)$ 
and between usefulness and satisfaction ( $\square=0.24$, $\mathrm{p}<0.001, \mathrm{H} 2)$. Also, the results showed, benefit expectations positively relate with satisfaction ( $\square=0.48, \mathrm{p}<0.001, \mathrm{H} 3$ ). In addition, the relationship between satisfaction and continued intention to use was significant ( $\square=0.40, \mathrm{p}<0.001, \mathrm{H} 4)$. Finally, the results indicate a significant relationship between continued intention to use and location disclosure ( $\square=0.42, \mathrm{p}<0.001, \mathrm{H} 6)$. The only relationship that was not significant was the relationship between usefulness and continued intention to use, rejecting the H5.

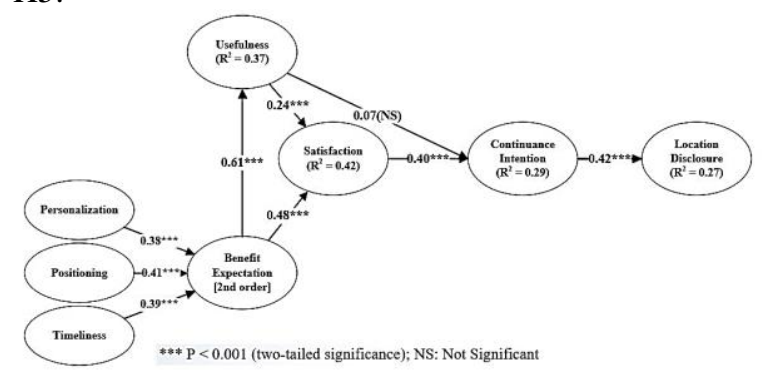

Figure 2. Structural analysis of the model

\section{Discussion}

This research investigated the continued intention to use LBAs and location disclosure from the expectation-confirmation theory (ECT) perspective. We explored the effect of benefit expectations (timeliness, personalization, and positioning) on the usefulness of LBAs. Further, we investigated the effect of usefulness on satisfaction and continued intention to use. The focus of research proposed that benefit expectations positively influence usefulness. It also proposed that usefulness influences both satisfaction and continued intention to use LBAs. From the ECT perspective, the level of satisfaction and usefulness of using LBA is results from the confirmation of benefit expectations calculus.

Results of the analysis indicated support for five of six hypotheses, excepting only the relationship between usefulness and intention to continue to use. We found that benefit expectations including timeliness, personalization, and positioning positively influence usefulness and satisfaction. We also found that usefulness of LBAs positively influence the satisfaction. One possible explanation for the insignificant relationship between usefulness and intention to continue to use LBAs is that human tendencies to continue using LBAs is defined only by satisfaction, instead of perceptions of usefulness. For example, if a navigation app that is definitely useful for steering to a destination cannot function offline, users would reject it. On the other hand, if the expectations of benefit are reasonably high, users would continue using such LBAs. LBA users may pursue certain benefits based on their a priori benefit expectations.

Another interesting finding is the relationship between usefulness and continued intention to use is fully mediated by the satisfaction level. The context of LBAs is consistent with the extended ECT study, indicating satisfaction and performance expectancy is the most important driver of continued intention to use mobile apps [65]. Our results indicate that the effect of perceived benefits on satisfaction is very strong; all three benefit expectations dimensions are at the same level of prominence. In addition, results demonstrate the location disclosure behavior is significantly determined by continued usage. This is an interesting finding for many businesses relying on location information disclosed by users. LBAs should always be considerate of what benefit users expect and in return the users keep using them and share their whereabouts.

\subsection{Implications}

This research contributes to theory and practice in the Information Systems (IS) discipline and related fields. On the theoretical side, using the ECT, 1) this research builds on the current gap in the literature about the continued usage of LBAs and location disclosure. This result strengthens current research, which focuses on mobile apps without attention to the type of app, the utility, and the type of informationwhich we provide. Through the ECT point of view, results indicate the importance of emphasizing on benefit expectations and satisfaction, rather than just risks, in order for the business to be successful in the continuance usage stage.

2) Theoretically, prior research has paid less accordance with respect to the effect of satisfaction on continued usage of LBAs and location disclosure. The findings of this study reveal, LBA users' decision to determine the weights expected benefits to continue using LBA is gauged through their satisfaction and the perception of usefulness of the app. The proposed research model can be used in other areas of IS research focusing on specific disclosed information to explain initial expectation and how users' choices under complex situations could change.

In addition, this study extends the literature on online location disclosure by focusing on the most important benefits of location disclosure that has not been studied before. The major body of the location disclosure focuses on the impact of consumers concerns such as privacy. However, this study emphasizes on the benefits instead of risks of location disclosure. 
3) The focus on location information generated using mobile apps could unravel more insights for future of business intelligence and location intelligence areas. In addition, the analytics of location information should apply more complex methods to uncover spatial patterns in location information due to the change of details in location information. While prior research has explored the continued usage of different technologies and mobile apps, there is a missing piece of the puzzle with regard to a type of apps known as LBAs and how disclosure of location information is influenced by users' satisfaction.

4) The new paradigms of data science and business intelligence embrace location intelligence of location information disclosed by users on mobile apps and devices. Location sharing behavior benefits users several ways. There are other types of benefits that may result from using LBAs and many users are initially unaware. Some of the other benefits resulting from users disclosing their locations include locatability, connectedness, and enjoyment [64]. For example, users can track family and friends or provide others with directions to specific locations. More importantly, when emergencies necessitate quickly pinpointing places, property, or people, users may experience untold benefits from location services [69].

5) Practically, findings of our study can be useful in future analytics applications such as in the area of Internet of things (IOT) because location is an inseparable part of all smart devices connected to the internet [37]. Practically, our model of location disclosure and continuance usage is useful for practitioners to understand how to maximize benefits for both users and the businesses as well as to encourage continuous usage of the application.

6) Mobile app users are reluctant to share their location knowing it diminishes their overall experience [21]. Not all users are comfortable with location sharing, as evidenced by $73 \%$ of smartphone and tablet users articulate that location sharing is either a somewhat or very useful task, $63 \%$ still are uncomfortable with disclosing their location [57]. Recent debacles resulting from location tracking via mobile apps have heightened risks such as privacy, financial, and time [36]. For example, Google was recently sued over tracking users' location even after the location tracking was set off by the mobile users [6]. Media sources describe negative consequences of sharing online location such as stalking, mugging, and robbery [71]. Developers should consider new privacy regulations and making sure users know how to remove their location history and geo-tagged digital footprints on LBAs. Also, future research can investigate risks of using LBAs and location disclosure behavior.

\subsection{Limitations and future research}

This study has several limitations. First, the survey data collection method imposes certain limitations on the interpretation of results. Here, survey subjects responded to items based on their perceptions, causing a social desirability bias to the analysis. In addition, app users questioned in the survey recalled their usage experience with LBAs, creating a potential misalignment between survey items and respondent recollection or usage. To remedy this issue, future researchers may wish to collaborate with mobile app developers, collecting actual usage data to increase both the precision and the value of this work.

Second, we selected respondents enrolled in a large public university. As a result, the age group consists mostly of young adults having an average age of 22 years. Although young adults are typical users of LBAs, results would be more generalizable with a more comprehensive sample from diverse age groups. Notwithstanding, students still provide a valid representative sample of general app user population: young adults exhibit higher interest, willingness to explore, and rates of adoption using new mobile apps, while being less hesitant to disclose their location [10].

\section{Conclusion}

For location intelligence to be effective, LBA users require detailed location information. Conditioned by positive expectations, mobile app developers and proprietors hope that mobile clients will use their apps extensively and continuously. Nonetheless, many mobile app users delete, uninstall, or stop using apps after just the first interaction. For mobile app purveyors to profit, convincing clients to use their app continuously is crucial. On the other hand, many of today's smartphones are location-enabled by default and allow users to share their whereabouts by default or intentionally.

This research fills the current research gap in the IS literature about the location intelligence and the complex usage of location-based apps. The current study investigated intention to continue using LBAs through the expectation-confirmation theory (ECT) perspective. Results showed while usefulness and satisfaction have direct effect on intention to continue using LBAs, the expectation benefits are indirectly related with intention to continue use. Finally, location disclosure is positively influenced by intention to continue using LBAs, indicating why location intelligence must encourage users to keep using apps so they can create location information. 


\section{References}

[1] Ajzen, I. and Fishbein, M. Understanding attitudes and predicting social. Behaviour. Englewood Cliffs, NJ: Prentice-Hall, (1980).

[2] Aloudat, A. and Michael, K. Toward the regulation of ubiquitous mobile government: a case study on locationbased emergency services in Australia. Electronic Commerce Research 11, 1 (2011), 31-74.

[3] Anderson Gerbing, David W., J.C. Structural Equation Modeling in Practice: A Review and Recommended TwoStep Approach. Psychological Bulletin 103, 3 (1988), 411423.

[4] Bharadwaj, A.S., Drnevich, P.L., Croson, D.C., et al. Issues in linking Information Technology Capability to Firm Performance. MIS Quarterly 29, 1 (2011), 125-165. [5] Bhattacherjee, A. Understanding information systems continuance: an expectation-confirmation model. MIS quarterly 25, 3 (2001), 351-370.

[6] Binder, M. Google sued over tracking locations even when "Location History" is off. Mashable, 2018. https://mashable.com/2018/08/20/google-location-historytracking-lawsuit/\#Hkg6pEAT7mqs.

[7] Böhmer, M., Hecht, B., Schöning, J., Krüger, A., and Bauer, G. Falling asleep with Angry Birds, Facebook and Kindle: a large scale study on mobile application usage. Proceedings of the 13th international conference on Human computer interaction with mobile devices and services, ACM (2011), 47-56.

[8] Boyles, J.L., Smith, A., and Madden, M. Privacy and data management on mobile devices. Pew Research Center's Internet \& American Life Project, 2012.

[9] Brown, S.A., Venkatesh, V., and Goyal, S. Expectation Confirmation in Information Systems Research: A Test of Six Competing Models. Mis Quarterly 38, 3 (2014). [10] Burstein, D. Mobile Marketing Chart: How likely millennials, baby boomers and Gen Xers are to delete your app. Marketing Sherpa, 2017.

https://www.marketingsherpa.com/article/chart/appdeletion-by-generation.

[11] Campbell, D.T. and Fiske, D.W. Convergent and discriminant validation by the multitrait-multimethod matrix. Psychological bulletin 56, 2 (1959), 81.

[12] Carto. State of Location Intelligence. 2018.

[13] Chen, R. Living a private life in public social networks: An exploration of member self-disclosure. Decision Support Systems 55, 3 (2013), 661-668. [14] Chen, R., Wang, J., Herath, T., and Rao, H.R. An investigation of email processing from a risky decision making perspective. Decision Support Systems 52, 1 (2011), 73-81.

[15] Chen, Z. and Dubinsky, A. A conceptual model of perceived customer value in e-commerce: A preliminary investigation. Psychology \& Marketing 20, 4 (2003), 323 347.

[16] Chia, P.H., Yamamoto, Y., and Asokan, N. Is this app safe?: a large scale study on application permissions and risk signals. Proceedings of the 21st international conference on World Wide Web, ACM (2012), 311-320. [17] Chin, W. Commentary: Issues and opinion on structural equation modeling. MIS quarterly 22, 1 (1998), vii-xvi.
[18] Chitturi, R., Raghunathan, R., and Mahajan, V. Delight by design: The role of hedonic versus utilitarian benefits. Journal of Marketing 72, 3 (2008), 48-63.

[19] Davis, F.D. Perceived usefulness, perceived ease of use, and user acceptance of information technology. MIS quarterly, (1989), 319-340.

[20] DeLone, W.H. and McLean, E.R. The DeLone and McLean Model of Information Systems Success : A TenYear Update. Journal of Management Information Systems 8, 4 (2013), 9-30.

[21] eMarketer. Mobile App Users Reluctant to Share Location - eMarketer. Mobile, 2015.

http://www.emarketer.com/Article/Mobile-App-UsersReluctant-Share-Location/1013276.

[22] eMarketer. Most Smartphone Owners Use LocationBased Services. Mobile, 2016.

https://www.emarketer.com/Article/Most-SmartphoneOwners-Use-Location-Based-Services/1013863. [23] eMarketer. Location Intelligence 2018: Consumer Behavior, Data Quality and Targeting Tips. 2018. [24] Festinger, L. A theory of cognitive dissonance. Stanford University Press, 1962.

[25] Fishbein, M. and Ajzen, I. Belief; attitude; intention; and behavior: An introduction to theory and research. Addison-Wesley, Reading, MA, 1975.

[26] Forbes. Data-Driven Retail: Extracting Value From Customer Data. 2018.

[27] Fornell, C. and Larcker, D.F. Evaluating structural equation models with unobservable variables and measurement error. Journal of Marketing Research 18, 1 (1981).

[28] Hulland, J. Use of partial least squares (PLS) in strategic management research: a review of four recent studies. Strategic management journal 20, 2 (1999), 195204.

[29] Karahanna, E., Straub, D.W., and Chervany, N.L. Information technology adoption across time: a crosssectional comparison of pre-adoption and post-adoption beliefs. MIS quarterly 23, 2 (1999), 183-213.

[30] Keith, M.J., Babb, J., Lowry, P.B., Furner, C., and Abdullat, A. The Roles of privacy assurance, network effects, and information cascades in the adoption of and willingness to pay for location-based services with mobile applications. Network Effects, and Information Cascades in the Adoption of and Willingness to Pay for Location-Based Services with Mobile Applications (June 30, 2013), (2013). [31] Kim, D.J., Ferrin, D.L., and Rao, H.R. Trust and Satisfaction, Two Stepping Stones for Successful ECommerce Relationships: A Longitudinal Exploration. Information Systems Research 20, 2 (2009), 237-257.

[32] King, I.M. King's Theory of Goal Attainment. Nursing Science Quarterly 5, 1 (1992), 19-26.

[33] Kline, R. Principles and practice of structural equation modeling. Guilford Publications, 2015.

[34] Koohikamali, M. Three Essays on Information Privacy of Mobile Users in the Context of Mobile Apps. 2016.

[35] Koohikamali, M., Gerhart, N., and Mousavizadeh, M. Location disclosure on LB-SNAs: The role of incentives on sharing behavior. Decision Support Systems 71, (2015). [36] Koohikamali, M. and Peak, D.A. Location-Based Mobile Applications Usage Behavior : Beware the Power of the Dark Side. Americas Conference on Information 
Systems, (2015).

[37] Lee, I. and Lee, K. The Internet of Things (IoT): Applications, investments, and challenges for enterprises. Business Horizons 58, 4 (2015), 431-440.

[38] Lee, M.-C. Factors influencing the adoption of internet banking: An integration of TAM and TPB with perceived risk and perceived benefit. Electronic Commerce Research and Applications 8, 3 (2009), 130-141.

[39] Lee, M.-C. Explaining and predicting users' continuance intention toward e-learning: An extension of the expectation--confirmation model. Computers \& Education 54, 2 (2010), 506-516.

[40] Liang, H., Saraf, N., Hu, Q., and Xue, Y. Assimilation of enterprise systems: the effect of institutional pressures and the mediating role of top management. MIS quarterly 31, 1 (2007), 59-87.

[41] Lin, C.S., Wu, S., and Tsai, R.J. Integrating perceived playfulness into expectation-confirmation model for web portal context. Information \& management 42, 5 (2005), 683-693.

[42] Lohmöller, J.-B. Latent Variable Path Modeling with Partial Least Squares. Springer, 2013.

[43] Lynn, M.R. Determination and quantification of content validity. Nursing research 35, 6 (1986), 382-386. [44] Nunnally, J.C. Psychometric theory. McGraw-Hill New York, The University of Michigan, 1967.

[45] Oliver, R.L. A cognitive model of the antecedents and consequences of satisfaction decisions. Journal of Marketing Research 17, 4 (1980), 460-470.

[46] Overby, J.W. and Lee, E.-J. The effects of utilitarian and hedonic online shopping value on consumer preference and intentions. Journal of business research 59, 10 (2006), 1160-1166.

[47] Paek, J., Ko, J., and Shin, H. A Measurement Study of BLE iBeacon and Geometric Adjustment Scheme for Indoor Location-Based Mobile Applications. Mobile Information Systems 2016, (2016).

[48] Peter, J.P. and Tarpey, L.X. A Comparative Analysis of Three Consumer Decision Strategies. Journal of Consumer Research 2, 1 (1975).

[49] Petter, S., Straub, D., and Rai, A. Specifying formative constructs in information systems research. Mis Quarterly 31, 4 (2007), 623-656.

[50] PewResearch. Mobile Technology Fact Sheet. 2014, 2014. http://www.pewinternet.org/fact-sheets/mobiletechnology-fact-sheet/.

[51] Pick, J.B., Turetken, O., Deokar, A. V., and Sarkar, A. Location analytics and decision support: Reflections on recent advancements, a research framework, and the path ahead. Decision Support Systems 99, (2017), 1-8. [52] Podsakoff, P.M., MacKenzie, S.B., Lee, J.-Y., and Podsakoff, N.P. Common method biases in behavioral research: a critical review of the literature and recommended remedies. Journal of applied psychology 88 , 5 (2003), 879.

[53] Poikela, M., Wechsung, I., and Möller, S. LocationBased Applications - Benefits, Risks, and Concerns as Usage Predictors. (2015), 1-7.

[54] Rajendran, V. Location Based Services : Expected Trends and Technological Advancements. Geo Awesomeness, (2017).

[55] Ringle, C.M., Wende, S., Will, A. SmartPLS 2.0 (M3) beta. Hamburg. http://www.smartpls.de, (2005).

[56] Sadeh, N., Hong, J., Cranor, L., et al. Understanding and capturing people's privacy policies in a mobile social networking application. Personal and Ubiquitous Computing 13, 6 (2009), 401-412.

[57] SalesForce and cloud, M. Mobile Behavior Report. Sales force, 2014.

[58] Satyanarayanan, M. Swiss Army Knife or Wallet? IEEE Pervasive Computing 4, 2 (2005), 2-3.

[59] Smith, A. Location-based apps present opportunities -and data challenges. TechTarget, 2014.

http://searchcrm.techtarget.com/feature/Location-basedapps-present-opportunities-and-data-challenges.

[60] Statista. Mobile App Usage - Statistics \&amp; Facts | Statista. 2015.

https://www.statista.com/topics/1002/mobile-app-usage/.

[61] Statista. Percentage of mobile subscribers in selected European countries using location-based services in 2014 and 2017. 2017.

https://www.statista.com/statistics/294314/share-of-mobilesubscribers-using-location-based-services/.

[62] Statista. Mobile App Usage - Statistics \& Facts. 2018. https://www.statista.com/topics/1002/mobile-app-usage/. [63] Sun, Y., Fang, Y., and Lim, K. Understanding knowledge contributors' satisfaction in transactional virtual communities: A cost-benefit trade-off perspective.

Information \& Management, (2014).

[64] Sun, Y., Wang, N., and Shen, X.-L. Perceived Benefits, Privacy Risks, and Perceived Justice in Location Information Disclosure: a Moderated Mediation Analysis. Pacific Asia Conference on Information Systems, AAIS (2014), 1-14.

[65] Tam, C., Santos, D., and Oliveira, T. Exploring the influential factors of continuance intention to use mobile Apps: Extending the expectation confirmation model. Information Systems Frontiers, (2018), 1-15.

[66] Tessem, B. and Nyre, L. The Influence of Social Media Use on Willingness to Share Location Information. In Trust, Privacy, and Security in Digital Business. Springer, 2013, 161-172.

[67] Thong, J.Y.L., Hong, S.-J., and Tam, K.Y. The effects of post-adoption beliefs on the expectation-confirmation model for information technology continuance.

International Journal of Human-Computer Studies 64, 9 (2006), 799-810.

[68] Tow, W.N.-F.H., Dell, P., and Venable, J. Understanding information disclosure behaviour in Australian Facebook users. Journal of Information Technology 25, 2 (2010), 126-136.

[69] Tsai, J.Y., Kelley, P.G., Cranor, L.F., and Sadeh, N. Location-sharing technologies: Privacy risks and controls. ISJLP 6, (2010), 119.

[70] Turel, O., Serenko, A., and Bontis, N. User acceptance of hedonic digital artifacts: A theory of consumption values perspective. Information \& Management, (2010).

[71] Wernke, M., Skvortsov, P., Dürr, F., and Rothermel, $\mathrm{K}$. A classification of location privacy attacks and approaches. Personal and Ubiquitous Computing 18, 1 (2014), 163-175.

[72] Werts, C., Linn, R., and Jöreskog, K. Intraclass reliability estimates: Testing structural assumptions. Educational and, (1974). 
[73] Xu, H., Teo, H.-H., Tan, B.C.Y., and Agarwal, R. The role of push-pull technology in privacy calculus: the case of location-based services. Journal of Management Information Systems 26, 3 (2009), 135-174.

\section{Appendix A. Measurement items}

\begin{tabular}{|c|c|c|c|}
\hline No & Construct & Measure & Reference \\
\hline 1 & \multirow{3}{*}{$\begin{array}{l}\text { Intention to } \\
\text { continue to use } \\
\text { (CUSE) }\end{array}$} & I intend to continue using LBAs rather than discontinue its use. & \multirow{3}{*}{ [5] } \\
\hline 2 & & My intentions are to continue using LBAs than use traditional ways to locate. & \\
\hline 3 & & If I could, I would never discontinue my use of LBAs. & \\
\hline 4 & \multirow{4}{*}{$\begin{array}{l}\text { Location } \\
\text { Disclosure } \\
\text { (DISC) }\end{array}$} & I am willing to disclose my location-related information using LBAs in the future. & \multirow[t]{4}{*}{ [73] } \\
\hline 5 & & I will probably disclose my location information using LBAs in the near future. & \\
\hline 6 & & When I use LBAs in the future, I will likely disclose my location. & \\
\hline 7 & & If there is a chance, I intend to disclose my location when I use LBAs. & \\
\hline 8 & \multirow{6}{*}{$\begin{array}{l}\text { Usefulness } \\
\text { (USEF) }\end{array}$} & Using LBAs improves my performance in finding places. & \multirow[t]{6}{*}{ [4] } \\
\hline 9 & & Using LBAs increases my effectiveness in finding locations. & \\
\hline 10 & & Overall, LBAs are useful in finding locations. & \\
\hline 11 & & Using LBAs improves my performance in getting directions. & \\
\hline 12 & & Using LBAs increases my effectiveness in getting directions. & \\
\hline 13 & & Overall, LBAs are useful in getting directions. & \\
\hline 14 & \multirow{3}{*}{$\begin{array}{l}\text { Personalization } \\
\text { benefit } \\
\text { (PEBEN) }\end{array}$} & The LBAs can provide me with personalized services tailored to my activity context. & \multirow[t]{3}{*}{ [73] } \\
\hline 15 & & $\begin{array}{l}\text { The LBAs can provide me with more relevant information tailored to my preferences or personal } \\
\text { interests. }\end{array}$ & \\
\hline 16 & & The LBAs can provide me with the kind of information or service that I might like. & \\
\hline 17 & \multirow{3}{*}{$\begin{array}{l}\text { Positioning } \\
\text { benefit } \\
\text { (POBEN) }\end{array}$} & With the LBAs I am able to get the up-to-date information/services whenever I need to. & \multirow[t]{3}{*}{ [73] } \\
\hline 18 & & With the LBAs, I am able to access the relevant information/services at the right place. & \\
\hline 19 & & With the LBAs, I am able to access the relevant information/services wherever I want to. & \\
\hline 20 & \multirow{3}{*}{$\begin{array}{l}\text { Timeliness } \\
\text { benefit } \\
(\mathrm{TBEN})\end{array}$} & With LBAs, I can get just-in-time information/services. & \multirow[t]{3}{*}{ [73] } \\
\hline 21 & & LBAs provide me an immediate response everywhere I need them. & \\
\hline 22 & & I get quick access to information/services I need anywhere I go because of LBAs. & \\
\hline 23 & \multirow{4}{*}{$\begin{array}{l}\text { Satisfaction } \\
(\mathrm{SAT})\end{array}$} & I am satisfied with the use of LBAs. & \multirow[t]{4}{*}{ [63] } \\
\hline 24 & & I am pleased with the use of LBAs. & \\
\hline 25 & & I am contended with the use of LBAs. & \\
\hline 26 & & I am delighted with the use of LBAs. & \\
\hline
\end{tabular}

Appendix B. Descriptive statistics and correlation coefficients of research constructs

\begin{tabular}{|c|c|c|c|c|c|c|c|c|c|}
\hline Construct & Mean (SD) & AVE & CR & CA & 1 & 2 & 3 & 4 & 5 \\
\hline BEN & $5.25(1.11)$ & 0.62 & 0.94 & 0.92 & 0.79 & & & & \\
\hline CUSE & $4.41(1.16)$ & 0.76 & 0.9 & 0.85 & 0.40 & 0.87 & & & \\
\hline DISC & $5.79(1.01)$ & 0.85 & 0.96 & 0.94 & 0.26 & 0.42 & 0.92 & & \\
\hline SAT & $5.28(1.11)$ & 0.82 & 0.95 & 0.93 & 0.62 & 0.44 & 0.36 & 0.91 & \\
\hline USEF & $5.39(1.27)$ & 0.88 & 0.98 & 0.97 & 0.61 & 0.28 & 0.28 & 0.53 & 0.94 \\
\hline
\end{tabular}

